\title{
Study of the Impact of Redundancy on the Reliability of Pumping units of Oil wells in West Siberia
}

\author{
Pyalchenkov D. V. ${ }^{1}$, Pyalchenkov V.A. ${ }^{1}$ \\ ${ }^{1}$ Tyumen Industrial University, Russian Federation, pjalchenkovdv@tyuiu.ru
}

\begin{abstract}
The paper considers the influence of the choice of the probability indicator of failure-free operation as the main parameter on the backup system of its individual elements to optimize the maintenance and repair system. The research material was data on the laws of the distribution of failures, the actual time between failures and the main causes of failures of downhole pumping equipment of production wells of the Tarasovskoye field of Rosneft-Purneftegaz company. The study showed that oil wells equipped with sucker rod pump units have greater operational reliability.

The main results of the study are the quantitative values obtained of the necessary reserve elements of pumping units at given optimal values of the probability of failure-free operation. When using the model proposed in the study for practical application in production, it is possible to carry out calculations while establishing other requirements for the optimal value of the probability of failure-free operation.
\end{abstract}

Key words : downhole pumps, pumping systems reliability, modeling of reserve elements, the distribution law of failures, optimization of maintenance of electric submersible pumps.

\section{INTRODUCTION}

At the present stage of development of the oil industry, most large fields have entered the late stage of development, which is characterized by a decrease in oil production, an increase in water cut in produced products, an aging well stock, etc. Due to the fact that at the present time the commissioning of new fields does not provide a significant increase in production volumes, and the applied physicochemical methods of intensification can only stabilize oil production, the main way to solve the problem of increasing production is to put wells into operation from the idle pool [1].

To stabilize the production of hydrocarbons, a large amount of geological and technical measures is required. These measures are carried out during the operation of production wells in conditions complicated by the processes of salt deposition, paraffin, tussing of directional wells, increasing depression on the formation, etc. During operation, corrosion processes intensify due to the appearance of hydrogen sulfide in the production of wells and an increase in water cut of produced products, which necessitates urgent measures to increase the corrosion resistance and strength of underground equipment. Significant material and labor resources are required to maintain the production fund of wells in working condition. All this creates a problem of evaluating the effectiveness of the applied maintenance and repair systems (TOR), which should be solved by the technical re-equipment of the oil and gas industry based on the introduction of more advanced equipment and technology for oil and gas production. And this is due to the urgent need to ensure their operational reliability, which is a function of factors of industrial, technical and operational nature [2,3]. The composition of each of the groups of factors, their impact on the value of maintainability characteristics is determined by the purpose and design features of the oil and gas field equipment, the conditions of its operation, maintenance and repair.

\section{METHODS}

One of the main tasks solved during the operation of systems is the task of ensuring their reliable operation. The severity of this problem is due to the complexity of technical devices and high values of operational loads. Therefore, reliability should be understood as the property of technical devices to perform specified functions, while maintaining their operational performance within specified limits for the required period of time or the required operating time in certain operating conditions $[1,4]$.

In practice, among other reliability indicators it is customary to operate with the average value of the overhaul period (MCI) regardless of the type of underground repair. Such an approach to assessing the activities of fisheries is completely untrue. The concept of MCI in the normative and technical documentation governing the conduct of repair work is usually absent. Its counterpart for wells is the average time between the current repairs, which characterizes the time between the wells and, on average, one current repair in the considered interval of the total operating time [5,7].

A feature of these tasks is that the system reliability indicator is expressed as the product of the corresponding reliability indicators of individual sections of the system:

$$
R\left(x_{1}, \ldots x_{m}\right)=\prod_{i=1}^{m} R_{i}\left(x_{i}\right)
$$


Pyalchenkov D. V. et al., International Journal of Emerging Trends in Engineering Research, 8(8), August 2020, 4366 - 4369

where $\mathrm{R}\left(\mathrm{x}_{1}, \ldots, \mathrm{x}_{\mathrm{m}}\right)$ - system reliability indicator, provided that at the 1 st site there are $x_{1}$ reserve elements, .., an $m$ site $-x_{m}$ reserve elements, $R_{i}\left(x_{i}\right)$ - reliability indicator of the $i$-th part of the system, provided that it contains $\mathrm{x}_{\mathrm{i}}$ backup elements $(\mathrm{i}=1,2, \ldots, \mathrm{m})$.

Usually, in optimal reservation problems, it is assumed that the "weight" of the system as a whole $\mathrm{W}(\mathrm{x} 1, \ldots, \mathrm{xm})$ is determined:

$W\left(x_{1}, \ldots, x_{m}\right)=\sum_{i=1}^{m} W_{i}\left(x_{i}\right)$

where $\mathrm{W}_{\mathrm{i}}\left(\mathrm{x}_{\mathrm{i}}\right)$ - "weight" of the $\mathrm{i}$-th element of the system, provided that it has $\mathrm{x}_{\mathrm{i}}$ spare elements [8].

The "weight" of the $i$-th component of the system is determined by:

$$
W_{i}\left(x_{i}\right)=w_{i} x_{i}
$$

where $\mathrm{w}_{\mathrm{i}}$ is the "weight" of one backup element used on the i-th part of the system.

In the presence of one limiting factor, two optimal reservation problems can be formulated.

The first task is to ensure that the reliability indicator is not less than the specified R0 with a minimum "weight" of the system as a whole, by redundantly reserving the system consisting of $\mathrm{m}$ sections.

This task can be written as: search $\min W\left(x_{1}, \ldots, x_{m}\right)$ provided that $R\left(x_{1}, \ldots, x_{m}\right) \geq R_{0}$.

The second task is to ensure, by separately reserving the system, consisting of $\mathrm{m}$ sections, that, at the maximum possible indicator of the system R, the "weight" of this system does not exceed the specified value $\mathrm{W}_{0}$.

\section{RESULTS}

This problem was solved by the method using the modified dynamic programming method $[6,9,13]$.

The initial data for the calculations were distribution laws for installations of sucker rod pumps (SHS) and electric centrifugal pumps (ESP) of the Tarasovskoye field of Rosneft-Purneftegaz company $[2,3,5,8]$.

Based on the calculation results, the graphical dependencies shown in figures 1-8 for ESP installations.

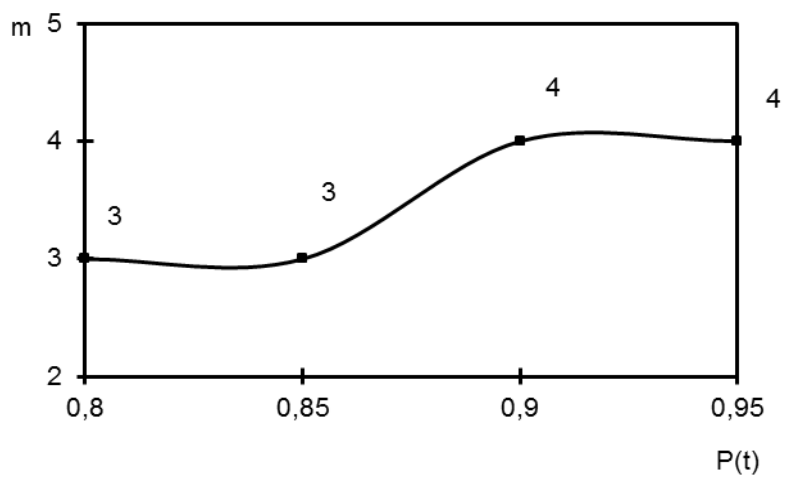

Figure 1: The dependence of the number of spare sets compensator from a given FBG (ESP)

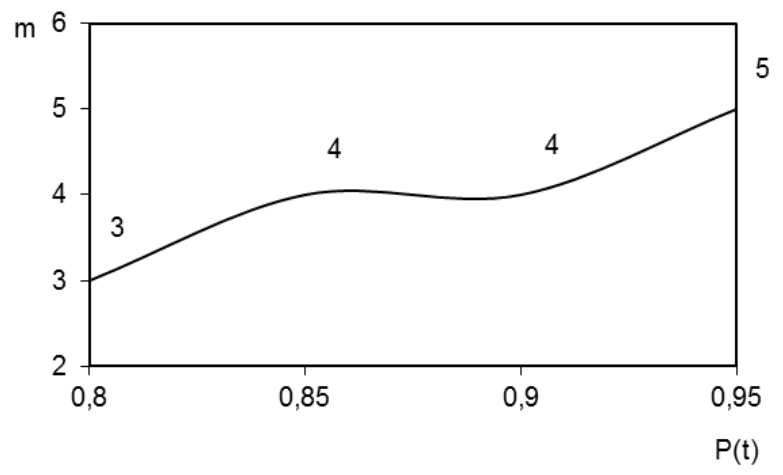

Figure 2: The dependence of the number of spare sets of connectors on a given FBG (ESP)

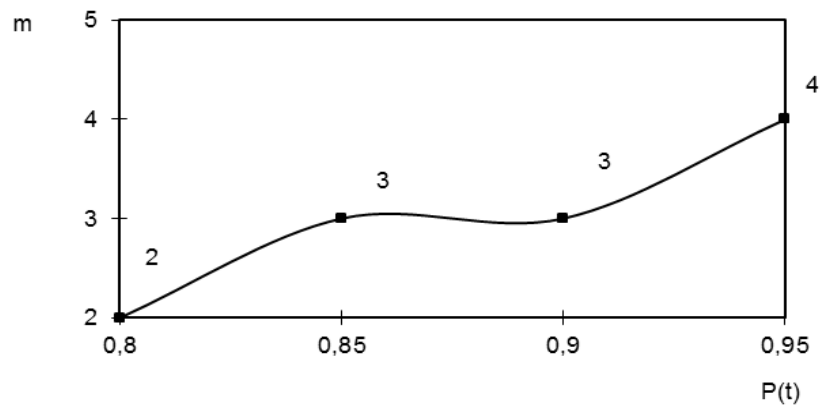

Figure 3: The dependence of the number of spare sets of hydraulic protection on a given FBG (ESP)

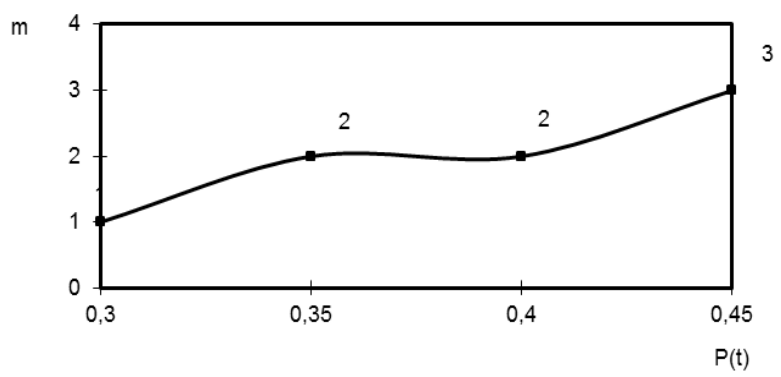

Figure 4: Dependence of the number of spare sets of impellers on a given FBG (ESP)

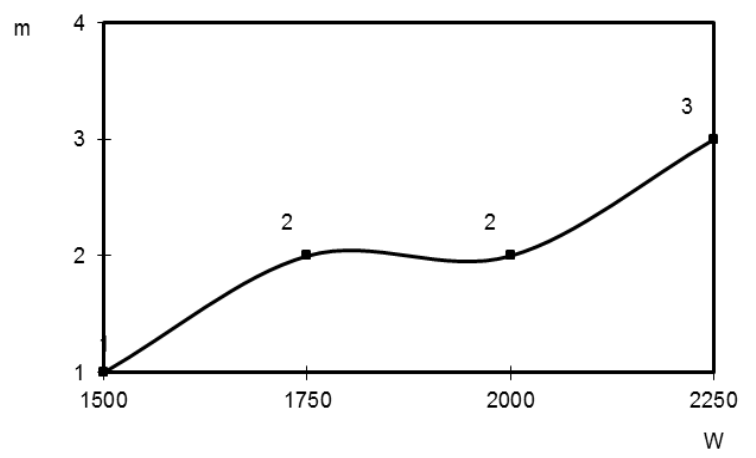

Figure 5: The dependence of the number of spare sets of compensator on the "weight" of the system (ESP) 
Pyalchenkov D. V. et al., International Journal of Emerging Trends in Engineering Research, 8(8), August 2020, 4366 - 4369

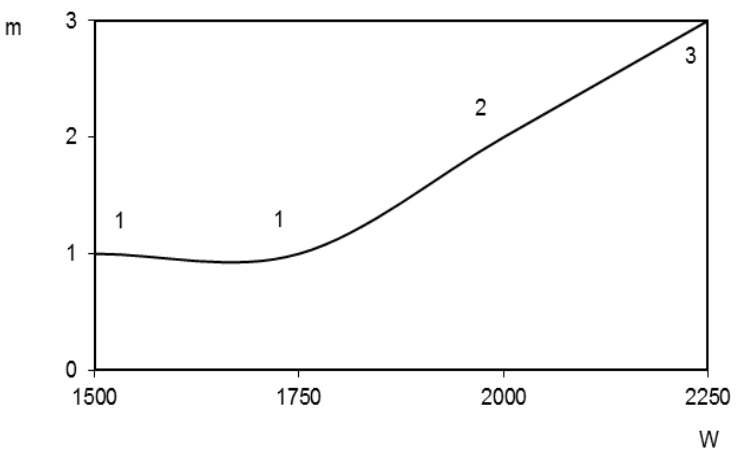

Figure 6: Dependence of the number of spare sets of plug connectors on the "weight" of the system (ESP)

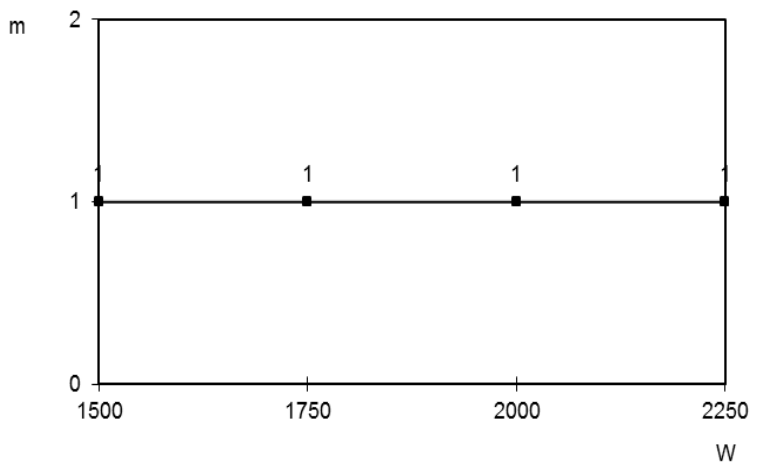

Figure 7: Dependence of the number of spare waterproofing kits on the "weight" of the system (ESP)

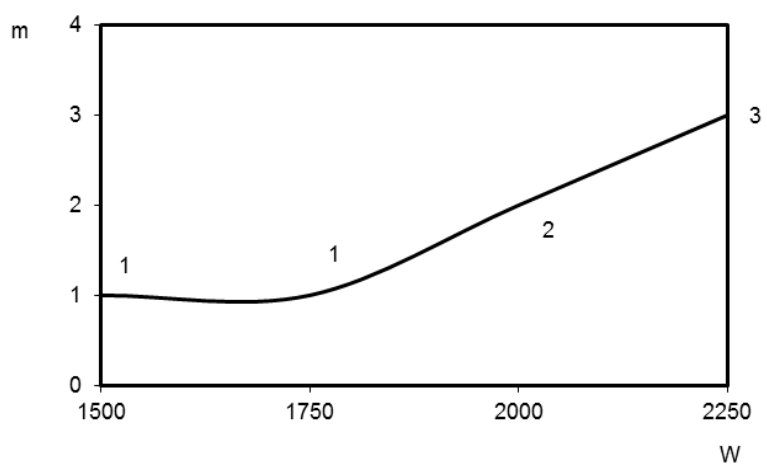

Figure 8: The dependence of the number of spare sets of impellers on the "weight" of the system (ESP)

In figure 1-4 shows the graphical dependencies for calculating the optimal backup task to achieve a certain reliability indicator of oil equipment, for which the probability of failure-free operation was taken. As initial limitations, the FBG was taken from 0.8 to 0.95 and the maximum "weight" of the system was $2500 \mathrm{cu}$ As can be seen from the graphs, the most reliable element in the installation are the impellers, which require from 1 to 3 sets to achieve FBG from 0.8 to 0.95 . The most unreliable element, according to the calculations, will be a plug, spare sets of which are required from 3 to 5 . Behind it are a compensator, which requires from 3 to 4 sets, and hydraulic protection, which requires from 2 to 4 sets. Based on these data, we can draw some conclusions that the company should adhere to the strategy of achieving FBG in the range from 0.8 to 0.9 , since when changing it from 0.8 to 0.95 , the number of spare sets of some nodes may change by 2 . For example, at $\mathrm{P}(\mathrm{t})=0.8$ and 0.95 , the number of spare sets of plug connectors will be 3 and 5 , and the sets of waterproofing 2 and 4 . Creating large stocks can negatively affect costs and absorb all the profit from a longer operation $[2,3,8,14]$.

The second group of figures (5-8) shows the results obtained when solving the problem according to the second method the method of limiting the "weight" of the system. Under the "weight" of the system, the cost of the entire installation as a whole was adopted, and under the "weight" of the element, its cost. The minimum value of FBG is 0.7 . As can be seen from the obtained dependences, the most reliable element in the system according to this technique is hydroprotection; for any admissible "weight" of the system, 1 spare set is required. A plug connector goes behind it and the impellers need from 1 to 3 sets when changing the "weight" from 1500 to 2250. The most unreliable element in the system, according to this method, is a compensator - it also requires 1 to 3 sets, but unlike from the previous elements with $\mathrm{W}=1750$, the indicator will be 2 units.

\section{DISCUSSION}

As can be seen from the graphs, the most reliable element of the installation according to the first method is a plunger pair - it requires 1 to 2 sets to ensure the required level of FBG, and the most unreliable valve seat, which requires 2 to 4 spare sets. The most optimal level of FBG can be considered its value of 0.85 , since with it the number of spare sets of valve seat, ball and shut-off valve will be 2 , and the plunger pair - 1 . At a value of $P(t)=0.9$, the number of required replacement kits for all items except the ball.

Considering the results of calculations according to the second model, we can say that the most reliable will also be a plunger pair, and the valve seat is the most unreliable part of the installation. The differences with the results of the first method are only in quantitative indicators, the level of which is lower in the second method, and the general trends will remain the same.

\section{CONCLUSION}

Comparing the results of calculations for both models, we can conclude that the $\amalg C H$ units have more durability than the ESP units. Firstly, the level of optimal FBG for SHS will be 0.85, and for ESP - 0.8. Secondly, in the ШCH installations, not a single component was identified, the backup sets of which are required more than 4 , while in the installation of ESP plug connectors, 5 are required. 
Pyalchenkov D. V. et al., International Journal of Emerging Trends in Engineering Research, 8(8), August 2020, 4366 - 4369

\section{REFERENCES}

1. Lysenko V.D., Grajfer V.I. Rational development of oil fields. Nedra. Moscow. 2005. Pp. 108-153.

2. R. J. Kuchumov, V. A. Pyalchenkov, D. V. Pyalchenkov. Methods for ensuring the reliability of operation of downhole equipment. TyumGNGU. Tyumen. 2005. Pp. 54-82.

3. Pyalchenkov D.V. Modeling reliability indicators of downhole equipment using the algorithm of "death and reproduction". Internet-journal "Naukovedenie». Vol. 5 (18), p.9, 2013.

4. Pyalchenkov D.V. Modeling reliability indicators of oil pumping units using redundancy. Internet-journal «Naukovedenie». Vol. 5 (18), p. 59, 2013.

5. Pyalchenkov V.A., Pyalchenkov D.V., Dolgushin V.V., Kulyabin G.A. (2016). Experimental Method for Measuring the Forces Acting On the Cutters of the Rolling Cutter Bit. Research Journal of Pharmaceutical, Biological and Chemical Sciences. Vol. 7(5). pp. 663-669, 2016.

6. Pyalchenkov V.A. A (2015). Bench for studying the load of the cutting structure of roller cone bits. Modern problems of science and education. Vol. 129. P. 413, 2015.

7. Pyalchenkov V.A., Dolgushin V.V., Kulyabin G.A. Work Capacity and Durability of Rolling Cutter Drill Bits (Analysis of Criteria and Research Results). Research Journal of Pharmaceutical, Biological and Chemical Sciences. Vol. 7(6). pp. 468-475, 2016.

8. Pyalchenkov, D. V., \& Pimnev, A. L. The research of tank sides geometrical forms after their long-term usage in the oil transportation system. Journal of Engineering and Applied Sciences. Vol 12(23), pp. 7150-7153, 2017.

9. Pyalchenkov V.A. Calculation of the load of the cutting elements of the bit. Modern problems of science and education. Vol. 121. P. 108, 2015

10. Grechin, E. G., Dolgushin, V. V., Pyalchenkov, V. A., Kuznetsov, V. G., \& Bastrikov, S. N. Designing the downhole drill string assembly with motor-deflector with four-point pattern of its interaction with borehole walls. Neftyanoe Khozyaystvo - Oil Industry. Vol. (9), pp. 82-85, 2017.

11. Pyalchenkov V.A. Calculation of the load of the cutting elements of the bit. Modern problems of science and education. Vol. 121. P. 281, 2015.

12. Simonov V.V., Vyskrebtsov V.G. Work of roller bits and their improvement. Nedra. Moscow. Pp. 153-186, 1975.

13. Makarishev, V. D., Savenko, G. A., \& Usikov, S. M. Determination of the optimal design of a thermal panel of an autonomous residential module by calculating temperature fields. International Journal of Emerging Trends in Engineering Research, 8(4), 1217-1221, 2020 https://doi.org/10.30534/ijeter/2020/4484202

14. Nadareishvili, G. G. Generalized models of processes occurring in neutralization systems. International Journal of Emerging Trends in Engineering Research, 8(1), 119-129, 2020

https://doi.org/10.30534/ijeter/2020/16812020 